\title{
An electrophysiological investigation into the automaticity of emotional face processing in high versus low trait anxious individuals
}

\author{
Amanda Holmes, Maria Kragh Nielsen, and Stephanie Tipper \\ Roehampton University, London, England \\ AND \\ Simon Green \\ Birkbeck University of London, London, England
}

\begin{abstract}
To examine the extent of automaticity of emotional face processing in high versus low trait anxious participants, event-related potentials (ERPs) were recorded to emotional (fearful, happy) and neutral faces under varying task demands (low load, high load). Results showed that perceptual encoding of emotional faces, as reflected in P1 and early posterior negativity components, was unaffected by the availability of processing resources. In contrast, the postperceptual registration and storage of emotion-related information, as reflected in the late positive potential component at frontal locations, was influenced by the availability of processing resources, and this effect was further modulated by level of trait anxiety. Specifically, frontal ERP augmentations to emotional faces were eliminated in the more demanding task for low trait anxious participants, whereas ERP enhancements to emotional faces were unaffected by task load in high trait anxious participants. This result suggests greater automaticity in processing affective information in high trait anxious participants.
\end{abstract}

Research has shown that emotional stimuli are prioritized for processing, with a number of studies demonstrating the capacity of, for instance, threat-related stimuli to draw attention rapidly and involuntarily. Evidence comes from a number of different experimental paradigms, including visual search tasks (e.g., Byrne \& Eysenck, 1995; Eastwood, Smilek, \& Merikle, 2001), visual probe and spatial cuing tasks (e.g., Fox, Russo, Bowles, \& Dutton, 2001; Holmes, Green, \& Vuilleumier, 2005; Mogg \& Bradley, 1999), and neuropsychological studies (Fox, 2002; Vuilleumier \& Schwartz, 2001).

Recent event-related potential (ERP) studies have also revealed a bias in selective attention toward emotional stimuli, such as face cues signaling a potential threat (e.g., Fox, Derakshan, \& Shoker, 2008; Holmes, Bradley, Kragh Nielsen, \& Mogg, 2009; Pourtois, Grandjean, Sander, \& Vuilleumier, 2004; Santesso et al., 2008). Progress has also been made in ERP research regarding the brain potential correlates of successive stages of emotional facial expression processing, particularly for threat-related emotions (fear and anger; see Eimer \& Holmes, 2007, and Vuilleumier \& Pourtois, 2007, for reviews). For example, results from scalp electrodes in some ERP studies have shown evidence for an enhanced P1 component (maximal typically at occipital locations, peaking at around $130 \mathrm{msec}$ ) in response to negative, relative to neutral or positive, facial expressions (e.g., Holmes, Kragh Nielsen, \& Green, 2008; Pizzagalli, Regard, \& Lehmann, 1999; Pourtois, Dan, Grandjean, Sander, \& Vuilleumier, 2005). This ERP effect has been attributed to enhanced sensory encoding in visual brain areas as a result of feedback from emotion evaluation centers (e.g., amygdala) in the brain, following the rapid perceptual detection of a motivationally significant stimulus (see, e.g., Vuilleumier \& Pourtois, 2007). Another posterior component, the early posterior negativity (EPN; maximal typically at lateral posterior and occipital locations at around and beyond $220 \mathrm{msec}$ ), shows an enhancement to negative (e.g., Eimer, Holmes, \& McGlone, 2003; Sato, Kochiyama, Yoshikawa, \& Matsumura, 2001; Schupp et al., 2004) and positive (e.g., Marinkovic \& Halgren, 1998; Schacht \& Sommer, 2009), relative to neutral, faces, and has also been linked to ongoing feedback from the amygdala to sensory cortices (see Eimer \& Holmes, 2007; Vuilleumier \& Pourtois, 2007). A further ERP deflection has been shown to arise at frontocentral locations in response to both negative and positive facial expressions; this is known as a late positive potential (LPP; arising beyond $\sim 250 \mathrm{msec}$ and most pronounced between 400 and $700 \mathrm{msec}$; see, e.g., Eimer \& Holmes, 2002; Krolak-Salmon, Fischer, Vighetto, \& Mauguière, 2001). Although the LPP typically arises at around $250 \mathrm{msec}$ poststimulus onset, some studies have 
shown that it can emerge earlier than this, between 160 and $250 \mathrm{msec}$ (see, e.g., Ashley, Vuilleumier, \& Swick, 2004; Eimer \& Holmes, 2002). It has been suggested in previous reports that the early phase of the LPP may be elicited via medial prefrontal mechanisms involved in the rapid detection of emotionally relevant stimuli in working memory (possibly via an amygdala-mediated "tag" on representations denoting salient events; see Eimer \& Holmes, 2007). It is possible that the early phase of the LPP is related to the P3a, in that the time course and topography of these two components are similar (see Eimer \& Holmes, 2007; Polich, 2007). The later phase of the LPP is considered to reflect the controlled storage or maintenance of a significant stimulus representation in working memory, enhancing its accessibility to higher order decision and response-related processes (see Eimer \& Holmes, 2007; cf. Tsuchiya \& Adolphs, 2007). The LPP is also referred to as a P3b (e.g., Schupp, Flaisch, Stockburger, \& Junghöfer, 2006), but it is unclear as to whether the LPP elicited by emotional faces truly reflects the same underlying processes as the standard $\mathrm{P} 3 \mathrm{~b}$ component, because the emotional face-related LPP tends to have a frontocentral maximal distribution (see, e.g., Eimer \& Holmes, 2007), in contrast to the centroparietal maxima for the $\mathrm{P} 3 \mathrm{~b}$ (see, e.g., Polich, 2007). It is clear that further research is required to uncover the extent to which the LPP and P3 components represent common underlying processes. P1, EPN, and LPP deflections to emotionally salient nonface stimuli have also been observed (see Olofsson, Nordin, Sequeira, \& Polich, 2008; Schupp et al., 2006), suggesting that these effects are not face specific, but can also be elicited by other kinds of emotional information.

ERPs are ideally suited to an analysis of the processing stages involved in the encoding of facial affect because they provide measures of electrical brain activity at high temporal resolution. An important and controversial issue is the extent to which these processing stages are obligatory or "automatic" (see Palermo \& Rhodes, 2007; Pessoa, 2005; Schupp et al., 2006). One position holds that subcortical emotion centers (e.g., the amygdala) subserve the automatic processing of emotional stimuli, independently of attentional resources (e.g., Dolan \& Vuilleumier, 2003). A second position states that the availability of attentional resources is necessary for detecting emotion (e.g., Pessoa, McKenna, Gutierrez, \& Ungerleider, 2002; Pessoa, Padmala, \& Morland, 2005). To address this issue, some recent ERP studies have investigated the impact of covert spatial attention on emotion-related ERP effects (e.g., Eimer et al., 2003; Holmes, Vuilleumier, \& Eimer, 2003). The findings from these studies revealed that both shortlatency as well as sustained longer-latency ERP emotional expression effects were evident when two emotional faces were presented at lateral locations and were attended for an emotion judgment task, whereas other stimuli in the visual array, such as a central pair of lines, were ignored. However, these ERP effects were eliminated when the emotional faces were ignored and participants focused their attention toward the alternative stimuli, such as central lines for a line length comparison task. This finding is clearly at odds with the suggestion that emotional facial expression is processed fully and automatically, irrespective of other current task demands.

In other studies, face stimuli have remained within the focus of spatial attention, and there has been a manipulation of the task relevance of the stimuli. Some sets of results have shown that emotion-related ERP modulations (including P1, EPN, and LPP) are impervious to the task relevance of emotional faces. For example, enhanced ERPs have been obtained not only when participants had to focus attention on the emotional expression of faces (e.g., Eimer et al., 2003) but also when observers did not need to explicitly judge the emotional content of faces, such as when deciding whether the same face had been presented twice in succession ( $n$-back task; e.g., Ashley et al., 2004; Eger, Jedynak, Iwaki, \& Skrandies, 2003; Halgren, Raij, Marinkovic, Jousmaki, \& Hari, 2000). Emotion-related ERP responses have also been observed when faces were entirely task irrelevant (e.g., Batty \& Taylor, 2003; Eimer \& Holmes, 2002; Holmes, Winston, \& Eimer, 2005; Pourtois et al., 2004), such as when infrequent pictures of houses were to be detected, with faces requiring no response. These results are suggestive of a degree of automaticity for emotional face processing under some conditions. Other studies, however, have shown dependence of emotion-related ERP effects on the nature of the task. For example, some late ERP responses to emotional faces were found to arise only when facial expression judgments were to be made, but not when decisions on facial identity or gender were required (e.g., Krolak-Salmon et al., 2001; Münte et al., 1998; Streit et al., 1999).

Clearly, under some circumstances, such as when the opportunity for the filtering of emotional faces by spatial attention is maximized, ERP modulations by the emotional content of faces may be abolished. Conversely, in circumstances in which attempts at spatial filtering are either not optimal or not required, emotional expression ERP differences may be present. However, these emotion-related effects may be influenced by the relevance of the faces to the participants' task. It is unclear which methodological factors may underlie the varying effects of task relevance on emotional expression processing. One possibility is that the processing load or difficulty of the task is an important contributing factor. For example, gender or facial identity judgments may require more processing resources than does the detection of occasional images of houses in a series of faces. However, it is difficult to know the extent to which information-processing demands contribute to facial expression ERP differences across these tasks, because the nature of the stimulus features to be selected has usually varied along with the levels of task difficulty. A primary aim of the present investigation, therefore, was to manipulate level of task difficulty while holding constant the nature of the stimulus attributes to be attended. Specifically, we were interested in whether emotional facial expression ERP effects would be attenuated when task difficulty (or task load) was increased. The present study also sought to explore whether potential attenuations in the ERP waveform would vary in magnitude across different stages of facial expression processing (e.g., at perceptual [P1, EPN] vs. postperceptual [LPP] stages), particu- 
larly since previous manipulations of task relevance have found effects on later as opposed to earlier ERPs (e.g., Krolak-Salmon et al., 2001). The results should inform us further as to the extent to which early versus late stages of emotional face processing may depend on the availability of information processing resources.

A further aim of the study was to examine the potential role of trait anxiety on ERP correlates of emotional facial expression processing under conditions of varying task difficulty. Fox, Russo, and Georgiou (2005) suggested that variation in anxiety may be a key factor in determining the extent to which emotion processing occurs automatically and independently of attention. Behavioral research into the effects of anxiety on emotion-attention interactions has revealed a greater tendency for individuals who were high as opposed to low in either clinical or nonclinical trait anxiety to orient and to sustain attention toward the location of angry or fearful faces (for reviews, see BarHaim, Lamy, Pergamin, Bakermans-Kranenburg, \& van Ijzendoorn, 2007; Fox, 2004; Mogg \& Bradley, 2004). Moreover, Fox et al. (2005) revealed that high-anxiety participants were more likely to detect fearful faces in an attentional blink task than were low-anxiety participants. These results are suggestive of enhanced automaticity of emotion processing in anxious individuals. To investigate this further, we planned to examine whether emotion processing, as measured by ERPs, would be less influenced by concurrent task processing demands in high relative to low trait anxious participants. Such a pattern of results would be indicative of greater obligatory processing of emotional information in high anxiety individuals. It should be noted here that a number of previous investigators have found anxiety and depression to be indistinguishable in nonclinical samples (see Fountoulakis et al., 2007). Some researchers have proposed that both measures may be components of a general psychological distress process or of negative affectivity (Clark \& Watson, 1991; Endler, Cox, Parker, \& Bagby, 1992). In this article, therefore, the term anxiety, as in many other self-report anxiety studies, is used in its broadest sense to encompass aspects of general distress as opposed to "pure" anxiety.

In order to test these predictions, we measured ERPs (specifically, P1, EPN, and LPP) in response to centrally presented fearful, neutral, and happy facial expressions. Participants' task was to detect repetitions of face stimuli (the $n$-back task). There were two levels of demand: The first had a low level of difficulty (1-back task; see Holmes et al., 2008) and the second had a high level of difficulty (2-back task). If emotional responses to facial threat are affected by task difficulty, we should expect to find differential effects of task load (1-back vs. 2-back) on emotional expression ERP effects for fearful and happy, relative to neutral, faces. If anticipated effects of emotional expression are modulated by trait anxiety level, with greater automaticity for the processing of emotionally salient information in high trait anxious participants, we should expect to find that emotion-related ERP modulations are more resistant to manipulations of task load in high relative to low trait anxious participants.
Happy facial expressions were included in this investigation because, although many behavioral and psychophysiological studies have demonstrated anxietyrelated effects that are specific for aversive stimuli, a few studies suggest that the bias may not be specific for threat. This emotionality hypothesis proposes that anxious individuals show biases for both negative and positive material (e.g., Bradley, Mogg, White, Groom, \& de Bono, 1999; Chen, Lewin, \& Craske, 1996; Garner, Mogg, \& Bradley, 2006; Mogg \& Marden, 1990). Comparable effects of anxiety on ERPs to both fearful and happy (relative to neutral) faces would be consistent with the emotionality hypothesis, whereas dissociable patterns of ERP responses to fearful and happy (relative to neutral) faces would provide evidence consistent with a valence-specific (e.g., threat-specific) hypothesis. ${ }^{1}$ Behavioral performance for correct detections of face repetitions was also recorded to assess participants' attention to the ongoing task.

\section{METHOD}

\section{Participants}

The participants were 70 healthy volunteers primarily from a college undergraduate population. Eight participants were excluded because of excessive eye blinks and other muscle artifacts during EEG recording, so that 62 participants ( 20 male and 42 female; 18-53 years old; average age, 27.0 years) remained in the sample. All participants had normal or corrected-to-normal vision, and the majority $(n=58)$ were right-handed. Scores on the State-Trait Anxiety Inventory (STAI; Spielberger, Gorsuch, Lushene, Vagg, \& Jacobs, 1983) trait anxiety scale were ranked and a tertile split was performed (lower tertile $=30$; upper tertile $=41$; range, 22-64) . The 18 participants who scored above the upper tertile were allocated to the high trait anxiety group; the 19 who scored below the lower tertile were allocated to the low trait anxiety group (see, e.g., Holmes, Richards, \& Green, 2006). See Table 1 for the characteristics of the two selected anxiety groups.

\section{Stimuli}

Photographs of faces of 10 individuals, 5 male and 5 female, were used as stimuli. All were taken from a standard set of pictures of facial affect (Ekman \& Friesen, 1976). Facial expression was fearful, happy, or neutral, resulting in a total of 30 different face images. All stimuli were presented at fixation on a black background and covered a visual angle of $8.6^{\circ} \times 5.7^{\circ}$. Stimuli were presented on a 17 -in. ViewSonic G220f computer monitor with a $75-\mathrm{Hz}$ refresh rate, connected to a Pentium IV-based Dell Precision computer. Stimulus presentation was controlled with E-Prime software (Schneider, Eschman, \& Zuccolotto, 2002).

\section{Table 1}

Mean Scores and Standard Deviations

for Questionnaire Measures of Trait Anxiety, State Anxiety, and Depression, for High Trait Anxious $(n=18)$ and Low Trait Anxious $(n=19)$ Groups

\begin{tabular}{lcrrrr}
\hline & \multicolumn{2}{c}{ High Trait Anxiety } & & \multicolumn{2}{c}{ Low Trait Anxiety } \\
\cline { 2 - 3 } \cline { 5 - 6 } \multicolumn{1}{c}{ Variable } & $M$ & $S D$ & & $M$ & $S D$ \\
\hline STAI trait anxiety & 50 & 7 & & 27 & 3 \\
STAI state anxiety & 39 & 12 & & 26 & 6 \\
Beck Depression Inventory & 13 & 6 & & 4 & 4 \\
Age (years) & 26 & 7 & & 25 & 7 \\
\hline
\end{tabular}

Note-STAI, State-Trait Anxiety Inventory. 


\section{Procedure}

Participants were seated in a dimly lit laboratory, and a computer screen was placed at a viewing distance of $70 \mathrm{~cm}$. Two task conditions were run, each consisting of two successive experimental blocks. In the 1-back task, participants were instructed to monitor the centrally presented faces and to respond with a dominant-hand buttonpress whenever the face they had just observed was identical (i.e., in terms of both identity and facial expression) to the face that had appeared one place back in the sequence. In the 2-back task, participants were asked to respond whenever the face they had just observed was identical to the one that had appeared two places back in the sequence. Each block consisted of 120 nontarget trials $(40 \times$ fearful, $40 \times$ happy, $40 \times$ neutral $)$ and 24 target trials $(8 \times$ fearful, $8 \times$ happy, $8 \times$ neutral). Thus, there were 240 nontarget trials and 48 target trials in total for each of the 1- and 2-back tasks (i.e., 480 nontarget and 96 target trials across the entire experiment). In the 2-back task, an additional 24 filler trials $(8 \times$ fearful, $8 \times$ happy, $8 \times$ neutral) were used for presenting between two identical face images in the sequence. The nontarget and target trials of faces with fearful, happy, and neutral emotional expressions were presented in a new random order for each participant within each block. All trial and stimulus types were equiprobable across the four experimental blocks. Participants were asked to respond as quickly as possible with a dominant-hand buttonpress only to repetitions of stimuli as instructed, and they were asked to maintain central fixation. The order in which the two task conditions were presented was counterbalanced across participants, and each task condition began with a short practice block. Stimuli were presented for $300 \mathrm{msec}$ and were separated by $1,200-\mathrm{msec}$ intertrial intervals.

\section{EEG Recording and Data Analysis}

EEG was recorded and processed using a Neuroscan SynAmps 64-channel device. Four facial bipolar electrodes placed on the outer canthi of the eyes and in the inferior and superior areas of the left orbit were used to record horizontal and vertical EOGs. Scalp EEG was recorded from $62 \mathrm{Ag} / \mathrm{AgCl}$ electrodes mounted in a quickcap (extended 10-20 system). All electrodes were referenced online to one electrode (vertex) and bandpass filtered at $0.01-100 \mathrm{~Hz}$. The impedance for electrodes was generally kept below $5 \mathrm{k} \Omega$, and EEG and EOG were sampled online with a digitization rate of $1000 \mathrm{~Hz}$. Following EEG recording, data were down-sampled to $250 \mathrm{~Hz}$ to save later computation time and were digitally filtered with a lowpass filter at $40 \mathrm{~Hz}$; all channels were re-referenced using the average of the mastoids (M1 and M2). EEG and HEOG were epoched offline relative to a 100-msec prestimulus baseline and extending for $800 \mathrm{msec}$ after stimulus presentation. Trials with lateral eye movements (HEOG exceeding $\pm 30 \mu \mathrm{V}$ ), as well as trials with vertical eye movements, eye blinks, or other artifacts (a voltage exceeding $\pm 60 \mu \mathrm{V}$ at any electrode) measured after target onset were excluded from analysis. To avoid any contamination from movement-related artifacts, ERP analyses were restricted to nontarget trials where no manual response was recorded, and data from target trials, filler trials, and trials with false alarms were removed. This resulted in the rejection of $40 \%$ of trials. ${ }^{2}$

Separate averages were computed for all combinations of task (1-back, 2-back), emotional expression (fearful, happy, neutral faces), and trait anxiety (high, low). ANOVAs were conducted on ERP mean amplitudes obtained for specific sets of electrodes. One set of frontocentral electrodes was defined a priori as a cluster on the basis of previous reports for the LPP (see Eimer \& Holmes, 2007; Holmes et al., 2008). Activity was analyzed at the following electrodes: F1, Fz, F2, FC1, FCz, FC2, C1, Cz, and C2, for regional analyses of frontocentral emotional facial expression effects within successive poststimulus time intervals of $180-400 \mathrm{msec}$ poststimulus (early phase LPP) and 400-700 msec poststimulus (late phase LPP). These time windows were selected on the basis of previous reports and inspection of individual subject waveforms. However, it should be noted that, although LPP modulations were most pro- nounced at frontocentral sites (see Figures 1 and 2), they exhibited a broad distribution across the scalp (see, e.g., Figure 3 for a depiction of waveforms at midline parietal electrodes). For EPN and P1 component effects, time windows and electrode sites were also determined on the basis of inspection of individual subject waveforms. This second set of electrodes consisted of occipital sites: $\mathrm{O} 1$ (left), Oz (mid), and O2 (right), within the 208- to 280-msec time window in order to examine EPN component effects and within the 124- to 164-msec poststimulus time window in order to isolate P1 component effects. Fewer electrode sites were selected for this analysis as compared with the LPP analyses, because maximal effects for P1 and EPN components are often constrained to a smaller number of electrode locations (see, e.g., Holmes et al., 2008). Separate averages were computed across these time windows and electrode positions, and the three electrode positions were entered as levels on an electrode position factor in the ANOVAs. The justification for comparing ERPs elicited at left, midline, and right recording hemisphere sites is that differential hemispheric effects have been observed previously for the P1 component (e.g., Holmes et al., 2008). Finally, in addition to performing omnibus ANOVAs across the P1, EPN, and LPP components, we conducted planned partial ANOVAs for 1- and 2-back tasks separately, for each component, in order to explore as fully as possible our research questions regarding the effects of task load on emotional expression ERP effects. For all analyses, Greenhouse-Geisser adjustments to the degrees of freedom were performed where appropriate. Further, all significant main or interaction effects involving trait anxiety were assessed further using BDI depression scores as a covariate measure, in order to examine the extent to which results may be specific to trait anxiety.

\section{Questionnaire Measures}

At the end of the session, participants completed a series of questionnaires including the state and trait versions of the STAI (Spielberger et al., 1983) and the Beck Depression Inventory (BDI; Beck, Ward, Mendelson, Mock, \& Erbaugh, 1961) - commonly used instruments for measuring anxiety and depression.

\section{RESULTS}

\section{Participant Characteristics}

See Table 1 for group details. The high trait anxiety group scored higher than the low trait anxiety group on trait anxiety $[t(35)=14.5, p<.001]$, state anxiety $[t(35)=4.1, p<.001]$, and BDI $[t(35)=5.5, p<.001]$, but did not differ in terms of age $[t(35)=0.1, p=.9]$.

\section{Behavioral Measures}

See Table 2 for performance accuracy and reaction times (RTs). Trials with false alarms constituted $1 \%$ of 1-back trials and $4 \%$ of 2-back trials. Mixed-design ANOVAs were conducted on both accuracy and RT data, with task (1-back, 2-back) and emotional expression (neutral, fearful, happy) as within-subjects factors and with trait anxiety group (high, low) as a between-subjects factor.

Accuracy. For the analysis of percentages of correct detections for target stimulus repetitions, there was a significant main effect of task $[F(1,35)=134.17, p<.001$, $\left.\eta_{\mathrm{p}}^{2}=.79\right]$, because accuracy was higher for the 1-back task $(83 \%)$ than for the 2-back task $(51 \%)$. There was also a significant main effect of emotional expression $\left[F(2,70)=7.55, p=.001, \eta_{\mathrm{p}}^{2}=.18\right]$, because performance was higher overall for fearful $(70 \%)$ as compared with neutral $(66 \%)$ or happy $(65 \%)$ facial expressions. 
A

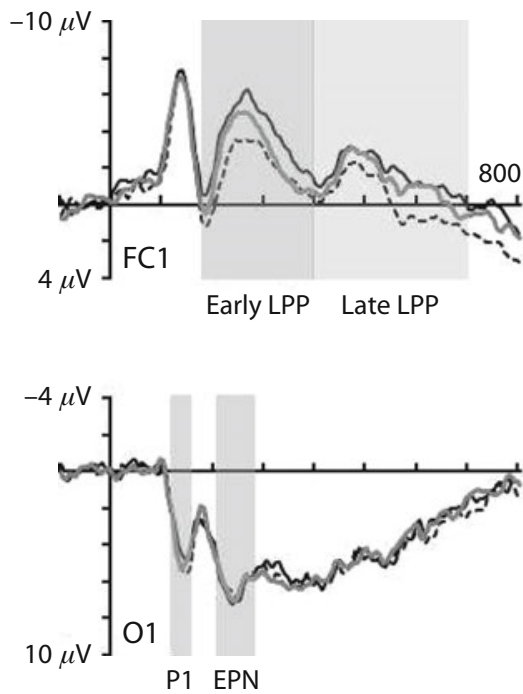

B
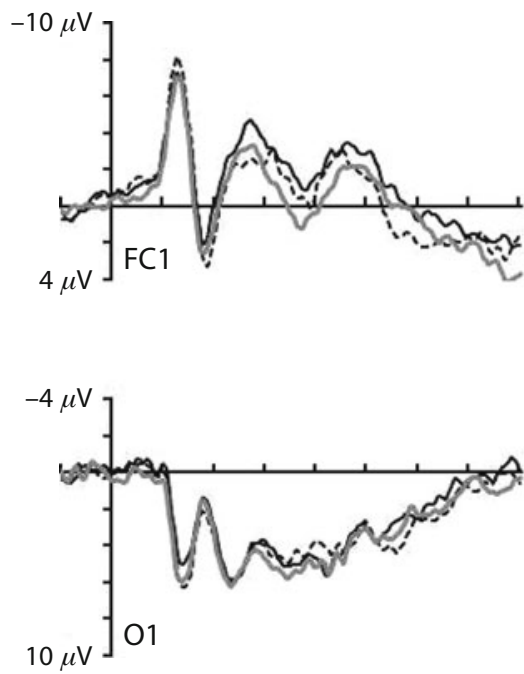

1-Back Task-Low Trait Anxiety Group

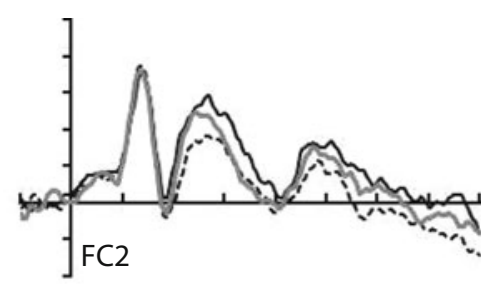

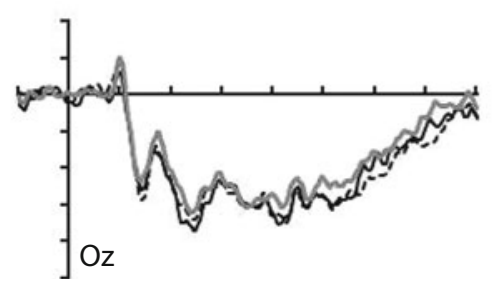

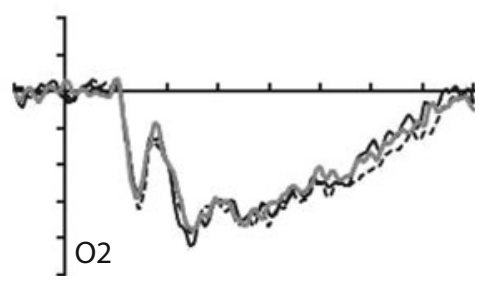

1-Back Task—High Trait Anxiety Group
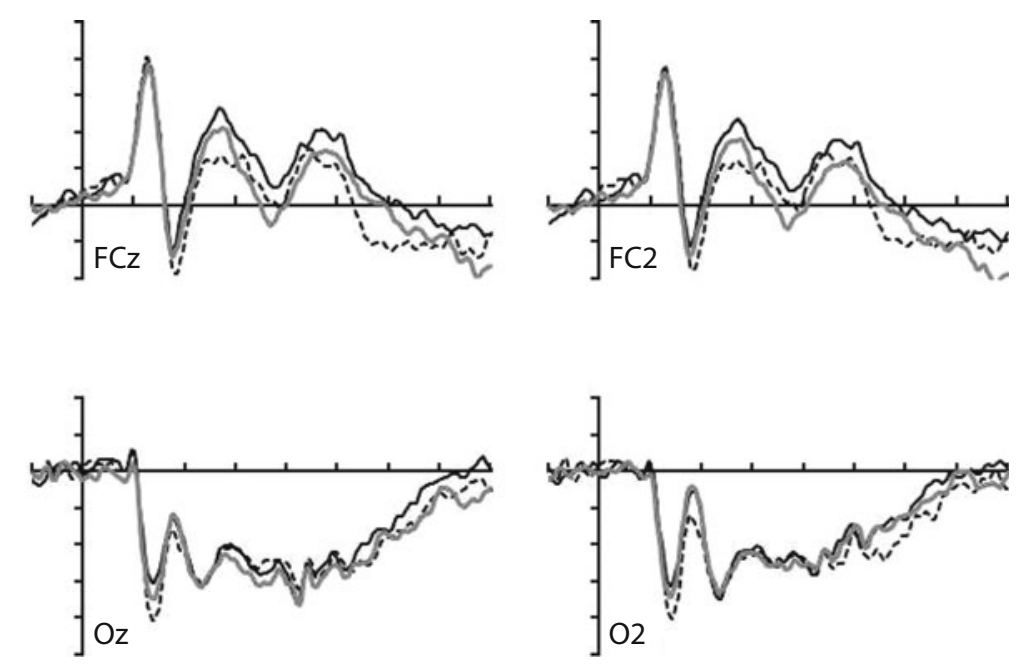

Fearful

Figure 1. Grand-averaged event-related potential (ERP) waveforms elicited at electrodes FC1, FCz, FC2 (a representative sample of frontocentral sites), $\mathrm{O} 1, \mathrm{Oz}$, and $\mathrm{O} 2$ in response to nontarget stimulus trials containing a neutral face (black solid line), a happy face (gray solid line), or a fearful face (dashed line). (A) ERPs elicited for the low trait anxiety group. (B) ERPs elicited for the high trait anxiety group. ERPs are shown for the 1-back task.

There were no other significant main or interaction effects (all $F \mathrm{~s}<2.4$, all $p \mathrm{~s}>.10$ ).

RTs. For the analysis of RTs for correct detections of target stimulus repetitions, there were no significant main or interaction effects (all $F_{\mathrm{s}}<1.3$, all $p \mathrm{~s}>.25$ ).

\section{ERP Measures}

Figure 1 shows ERPs for the 1-back task and Figure 2 shows ERPs for the 2-back task. Both figures show ERPs obtained in response to neutral faces (solid black lines), fearful faces (dashed lines), and happy faces (solid gray lines), separately for low trait anxious (top panel) and high trait anxious (bottom panel) participants.

\section{P1 Component at Occipital Locations (Poststimulus Measurement \\ Window $=124-164 \mathrm{msec}$ )}

A mixed ANOVA was conducted with trait anxiety (high, low), task (1-back, 2-back), emotional expression (neutral, fearful, happy), and electrode position (O1, Oz, O2) as factors. There was a significant main effect of emotional expression $\left[F(2,70)=9.95, p<.001, \eta_{\mathrm{p}}^{2}=\right.$ $.22]$, because the magnitude of the P1 component was greatest for fearful faces, smallest for neutral faces, and intermediate for happy faces. Paired-samples $t$ tests (with Bonferroni-corrected significance level of $p<.017$ ) showed that results for fearful faces differed from those for 
A
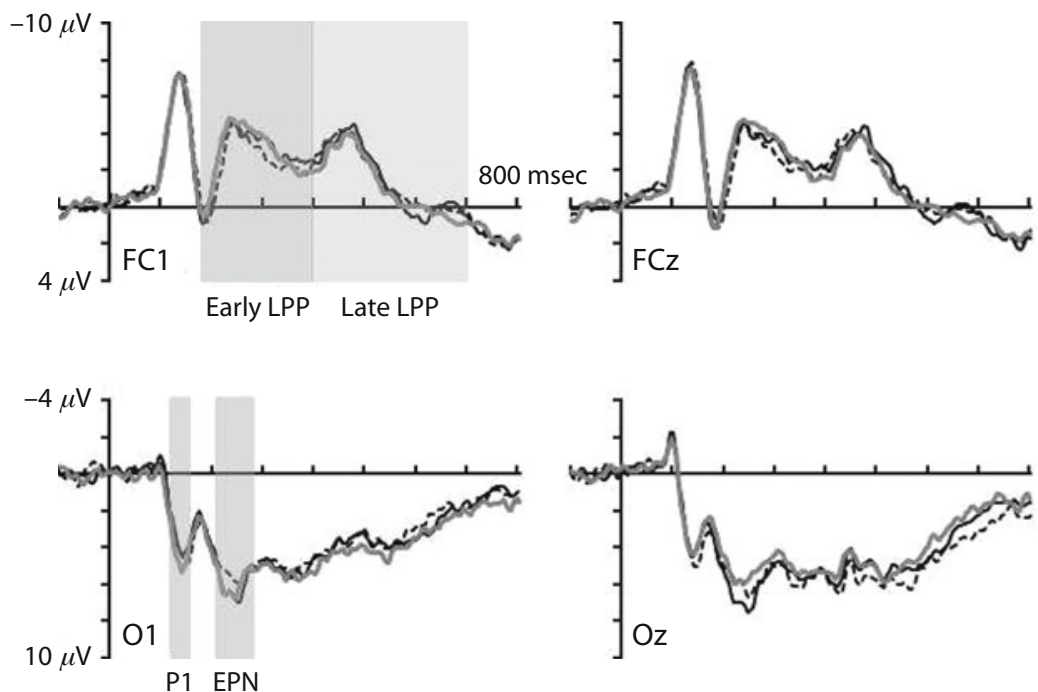

B
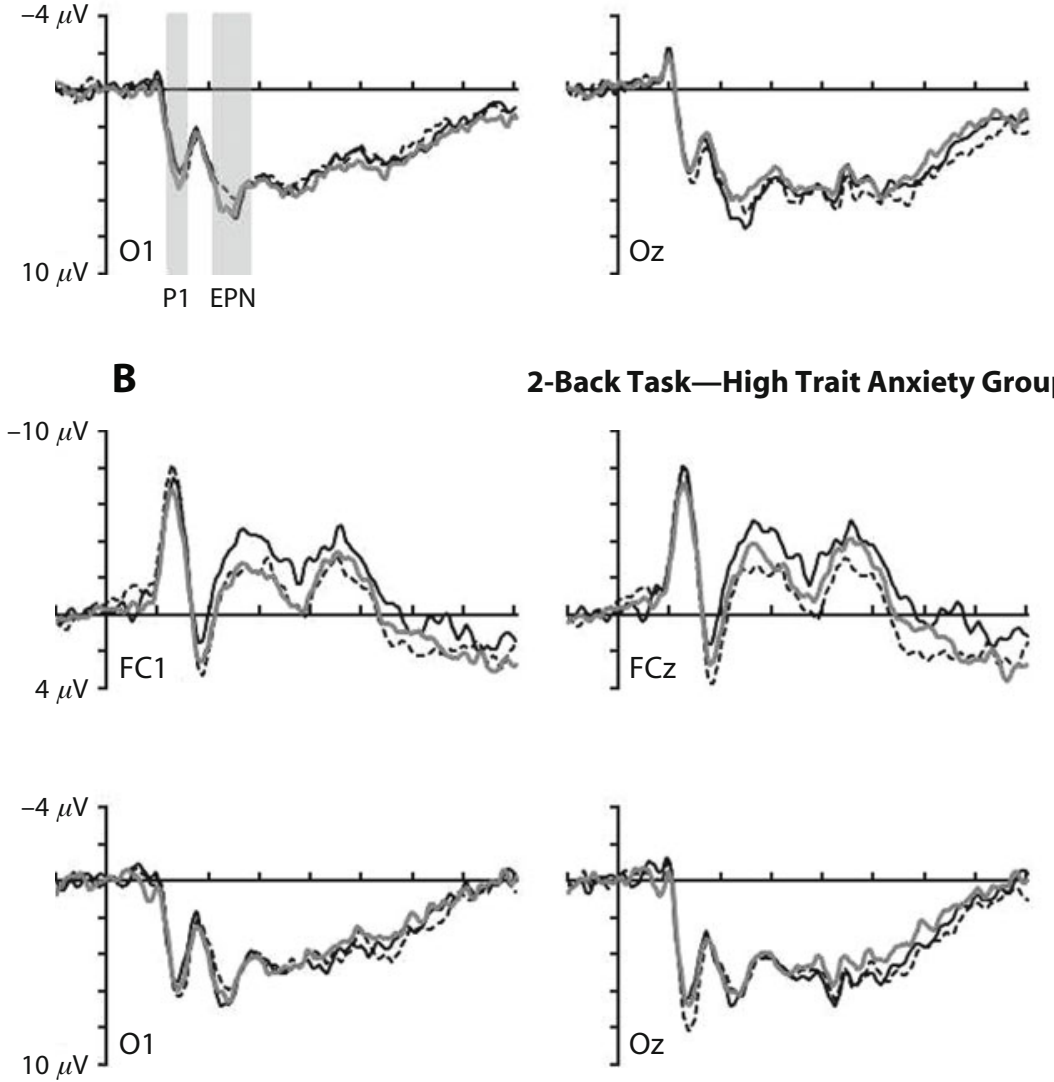

2-Back Task-High Trait Anxiety Group
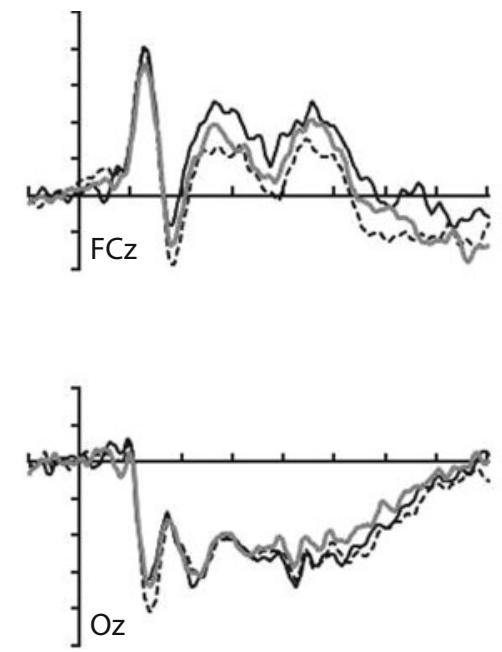

2-Back Task-Low Trait Anxiety Group

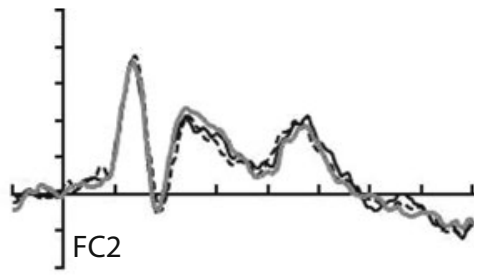

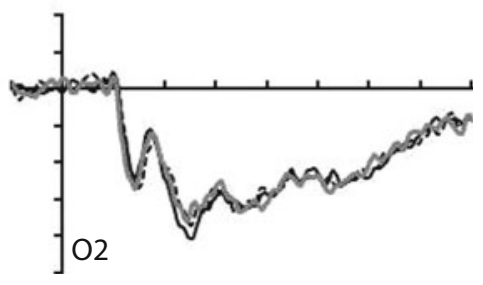
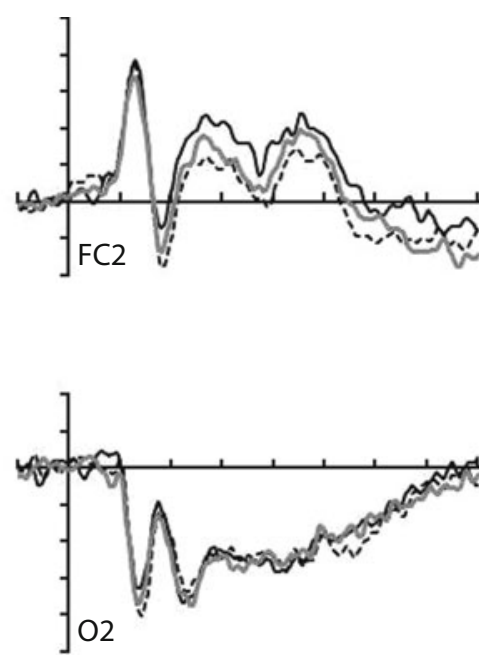

Neutral

Happy

Fearful

Figure 2. Grand-averaged event-related potential (ERP) waveforms elicited at electrodes FC1, FCz, FC2 (a representative sample of frontocentral sites), $\mathrm{O} 1, \mathrm{Oz}$, and $\mathrm{O} 2$ in response to nontarget stimulus trials containing a neutral face (black solid line), a happy face (gray solid line), or a fearful face (dashed line). (A) ERPs elicited for the low trait anxiety group. (B) ERPs elicited for the high trait anxiety group. ERPs are shown for the 2-back task.

neutral faces ( $p=.001, d=0.19$ ), but results for happy faces did not differ significantly from those for neutral or fearful faces. There was also a near-significant emotional expression $\times$ electrode position interaction $[F(4,140)=$ $\left.2.53, p=.064, \eta_{\mathrm{p}}^{2}=.07\right]$, which was subsumed under a significant task $\times$ emotional expression $\times$ electrode position interaction $\left[F(4,140)=3.04, p=.046, \eta_{\mathrm{p}}^{2}=.08\right]$. Here, the emotional expression effects described above were present across all electrode sites for the 1-back task, but appeared only to be present at $\mathrm{Oz}$ and $\mathrm{O} 2$ (midline and right hemisphere) for the 2-back task. There were no other significant main effects or interactions with emo- tional expression (all $F_{\mathrm{s}}<1.9$, all $p \mathrm{~s}>.15$ ). Planned ANOVAs conducted separately for 1- and 2-back tasks with factors of trait anxiety, emotional expression, and electrode position revealed patterns of results that were entirely consistent with those reported for the omnibus ANOVA.

\section{EPN at Occipital Locations (Poststimulus \\ Measurement Window $=\mathbf{2 0 8}-\mathbf{2 8 0} \mathbf{m s e c}$ )}

A mixed ANOVA was conducted with trait anxiety (high, low), task (1-back, 2-back), emotional expression (neutral, fearful, happy), and electrode position $(\mathrm{O} 1, \mathrm{Oz}$, 
A 1-Back Task—Low Trait Anxiety Group

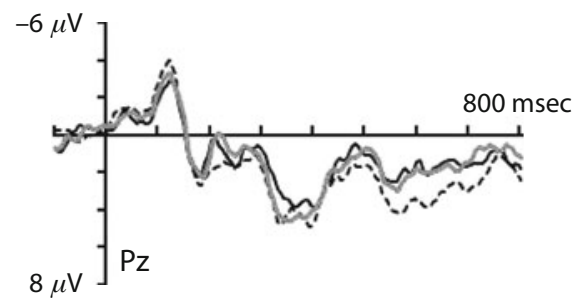

C 1-Back Task-High Trait Anxiety Group

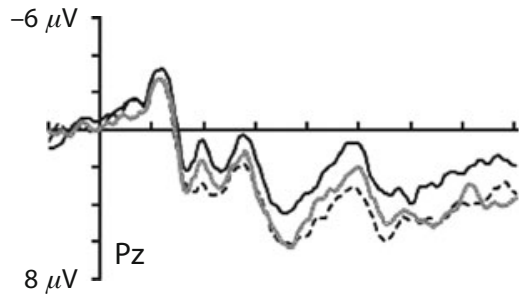

B 2-Back Task—Low Trait Anxiety Group

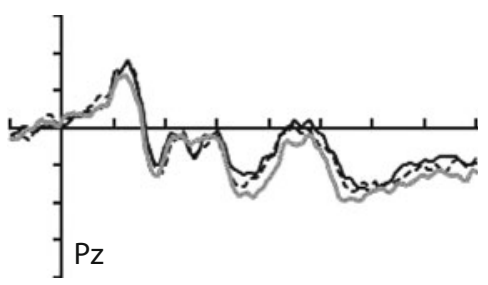

D 2-Back Task-High Trait Anxiety Group

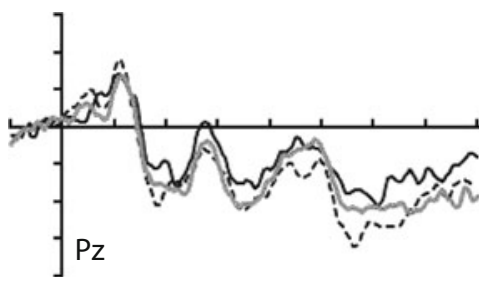

Neutral

Happy

Fearful

Figure 3. Grand-averaged event-related potential (ERP) waveforms elicited at electrode Pz in response to nontarget stimulus trials containing a neutral face (black solid line), a happy face (gray solid line), or a fearful face (dashed line). (A) ERPs elicited in the 1-back task for the low trait anxiety group. (B) ERPs elicited in the 2-back task for the low trait anxiety group. (C) ERPs elicited in the 1-back task for the high trait anxiety group. (D) ERPs elicited in the 2-back task for the high trait anxiety group. Although analyses were not conducted for the late positive potential (LPP) at parietal sites, because of the strong frontocentral distribution of the effect, parietal waveforms are presented here in order to provide an indication of the broad distribution of the LPP across the scalp.

O2) as factors. There was a significant main effect of emotional expression $\left[F(2,70)=3.93, p=.024, \eta_{\mathrm{p}}^{2}=\right.$ $.10]$, which was subsumed under a significant trait anxiety $\times$ emotional expression interaction $[F(2,70)=3.91$, $\left.p=.025, \eta_{\mathrm{p}}^{2}=.10\right]$. To unpack this interaction, partial one-way ANOVAs were conducted on the emotional expression factor separately for low and high trait anxious groups. There was a significant main effect of emotional expression for low trait anxiety participants $[F(2,36)=$ $\left.8.07, p=.001, \eta_{\mathrm{p}}^{2}=.31\right]$, because the EPN was enhanced to fearful and happy relative to neutral faces. Pairedsamples $t$ tests (with Bonferroni-corrected significance level of $p<.017$ ) showed that responses to fearful and happy faces differed from those to neutral faces $(p=$ $.061, d=0.35 ; p=.009, d=0.38$, respectively), but responses to fearful and happy faces did not differ significantly from each other. For high trait anxiety participants, however, there was no main effect of emotional expression $(F=1.2, p=.31)$. There were no other significant main effects or interactions with emotional expression from the omnibus ANOVA (all $F \mathrm{~s}<2.3$, all $p \mathrm{~s}>.08$ ). Planned ANOVAs conducted separately for 1- and 2-back tasks with factors of trait anxiety, emotional expression, and electrode position revealed patterns of results that were entirely consistent with the results reported from the omnibus ANOVA. Notably, the trait anxiety $\times$ emotional expression interaction from the omnibus ANOVA remained significant after using BDI scores as a covariate $\left[F(1,34)=13.16, p=.001, \eta_{\mathrm{p}}^{2}=.28\right]$.

\section{LPP at Frontocentral Locations}

(Early Phase: Poststimulus Measurement Window $=180-400 \mathrm{msec}$ )

A mixed ANOVA was conducted with trait anxiety (high, low), task (1-back, 2-back), and emotional expression (neutral, fearful, happy) as factors. There was a significant main effect of emotional expression $[F(2,70)=$ $\left.15.54, p<.001, \eta_{\mathrm{p}}^{2}=.31\right]$, because the LPP (early phase) was enhanced to fearful and happy relative to neutral faces. Paired-samples $t$ tests (with Bonferroni-corrected significance level of $p<.017$ ) showed that responses to fearful and happy faces differed from those for neutral faces $(p<.001, d=0.42 ; p=.002, d=0.28$, respectively), but responses to fearful and happy faces did not differ significantly from each other. There were no other significant main effects or interactions with emotional expression from the omnibus ANOVA (all $F \mathrm{~s}<1.9$, all $p \mathrm{~s}>.16)$. Planned ANOVAs conducted separately for 1- and 2-back tasks with factors of trait anxiety, emotional expression, and electrode position revealed significant main effects of emotional expression, consistent with the omnibus ANOVA. However, an emotional expression $\times$ trait anxiety interaction was also evident for the 2-back $\operatorname{task}\left[F(2,70)=3.67, p=.03, \eta_{\mathrm{p}}^{2}=.10\right]$. When this interaction was broken down, it was shown that the effect of emotional expression was present for high trait anxious participants $\left[F(2,34)=7.93, p=.001, \eta_{\mathrm{p}}^{2}=.32\right]$ but not for low trait anxious participants $(F=0.40, p=.67)$. Notably, after using BDI scores as a covariate, the emotional 
Table 2

Mean Percentage Accuracy and Reaction Times (RTs, in Milliseconds) for Correct Detections of Immediate Stimulus Repetitions in Each Condition for High Trait Anxious $(n=18)$ and Low Trait Anxious $(n=19)$ Groups

\begin{tabular}{|c|c|c|c|c|c|c|c|c|}
\hline \multirow{3}{*}{$\begin{array}{c}\text { Facial } \\
\text { Expression }\end{array}$} & \multicolumn{4}{|c|}{ Low Trait Anxiety } & \multicolumn{4}{|c|}{ High Trait Anxiety } \\
\hline & \multicolumn{2}{|c|}{ Accuracy } & \multicolumn{2}{|c|}{ RT } & \multicolumn{2}{|c|}{ Accuracy } & \multicolumn{2}{|c|}{ RT } \\
\hline & $M$ & $S D$ & $M$ & $S D$ & $M$ & $S D$ & $M$ & $S D$ \\
\hline \multicolumn{9}{|l|}{ 1-Back Task } \\
\hline Neutral & 84.4 & 13.1 & 598.8 & 115 & 78.3 & 18.6 & 580.2 & 97 \\
\hline Fearful & 88.9 & 10.6 & 588.4 & 10 & 80.9 & 17.4 & 585.8 & 105. \\
\hline Happy & 81.6 & 15.1 & 597.5 & 110.9 & 83.2 & 15.6 & 590.3 & 112.1 \\
\hline \multicolumn{9}{|l|}{ 2-Back Task } \\
\hline Neutral & 49.2 & 14.5 & 611.2 & 107. & 53.5 & 9.9 & 620.5 & 97.0 \\
\hline Fearful & 56.6 & 11.8 & 617.3 & 107.6 & 53.4 & 13.0 & 613.6 & 105.1 \\
\hline Happy & 46.0 & 13.4 & 596.0 & 112.5 & 47.0 & 14.0 & 605.4 & 118.5 \\
\hline
\end{tabular}

expression $\times$ trait anxiety interaction from the 2-back ANOVA was no longer significant $(F=2.36, p=.10)$

\section{LPP at Frontocentral Locations (Late Phase: Poststimulus Measurement Window $=400-700$ msec)}

A mixed ANOVA was conducted with trait anxiety (high, low), task (1-back, 2-back), and emotional expression (neutral, fearful, happy) as factors. There was a significant main effect of emotional expression $[F(2,70)=$ $\left.7.74, p=.001, \eta_{\mathrm{p}}^{2}=.18\right]$, which was subsumed under a significant task $\times$ emotional expression $\times$ trait anxiety interaction $\left[F(2,70)=3.26, p=.044, \eta_{\mathrm{p}}^{2}=.09\right]$. We broke down this interaction effect by examining 1-and 2-back tasks separately. For the 1-back task, there was a significant main effect of emotional expression $[F(2,70)=5.82$, $\left.p=.005, \eta_{\mathrm{p}}^{2}=.14\right]$, because the LPP (late phase) was greatest in magnitude to fearful faces, smallest in magnitude to neutral faces, and intermediate to happy faces. Paired-samples $t$ tests (with Bonferroni-corrected significance level of $p<.017$ ) showed that responses to fearful faces differed from responses to neutral faces $(p=.002$, $d=0.40$ ), but responses to happy faces did not differ significantly from responses to neutral or fearful faces. The main effect of emotional expression was not modulated by trait anxiety $(F=0.05, p=.95)$. For the 2-back task, there was a main effect of emotional expression $[F(2,70)=$ $\left.3.49, p=.045, \eta_{\mathrm{p}}^{2}=.09\right]$, which was subsumed under a significant trait anxiety $\times$ emotional expression interaction $\left[F(2,70)=4.29, p=.018, \eta_{\mathrm{p}}^{2}=.11\right]$. A partial ANOVA conducted on high trait anxious group data revealed a significant main effect of emotional expression $\left[F(2,34)=5.74, p=.007, \eta_{\mathrm{p}}^{2}=.25\right]$, because the LPP (late phase) was enhanced to fearful and happy relative to neutral faces. Paired-samples $t$ tests (with Bonferronicorrected significance level of $p<.017$ ) showed that responses to fearful and happy faces differed from those to neutral faces $(p=.010, d=0.50 ; p=.022, d=0.42$, respectively), but responses to fearful and happy faces did not differ significantly from each other. A second partial ANOVA on the low trait anxious group data, however, revealed no main effect of emotional expression $(F=0.20$, $p=.82$ ). It should be noted, however, that after using BDI scores as a covariate, the task $\times$ emotional expression $\times$ trait anxiety interaction from the omnibus ANOVA was no longer significant $(F=2.19, p=.12)$.

\section{DISCUSSION}

In order to investigate whether emotional expression ERP effects are susceptible to modulations by task load and anxiety level, we employed an $n$-back task with two levels of processing difficulty: low (1-back task) and high (2-back task). We identified ERP correlates of emotional face processing by comparing ERPs elicited on trials with neutral, fearful, and happy faces. These emotional expression effects were then compared across the low- and high-load tasks and across the low and high trait anxiety groups.

The behavioral results for the detection of face repetitions revealed that the 2-back task was significantly harder than the 1-back task, confirming the increased processing load. These task load results were not modified by differences in performance across trait anxiety groups or emotional facial expressions. Overall, however, participants were more accurate for the detection of fearful relative to happy and neutral faces. There were no differences in the patterns of RTs across the various conditions.

In contrast to the absence of behavioral performance interactions between face valence, processing load, and trait anxiety, modulations of emotional expression effects by task difficulty and trait anxiety were found in the ERPs, the patterns of which varied across distinct emotion-specific processing stages. For both of the posterior emotion-related components (P1 and EPN), fearful faces produced augmented effects relative to neutral faces, whereas happy faces triggered an enhancement in the EPN component but not in the P1. The presence of an enhanced visual P1 component to fearful faces coupled with the absence of an augmented P1 to happy faces replicates findings from a number of studies (e.g., Batty \& Taylor, 2003; Eger et al., 2003; Holmes et al., 2008; Pizzagalli et al., 1999; Pourtois et al., 2005; Streit et al., 1999). The P1 enhancement to fearful faces was stronger at midline and right hemisphere electrode positions than at the left hemisphere position in the 2-back task, which is consistent with a pattern of stronger emotion-related P1 effects at right hemisphere locations as revealed by some previous studies (e.g., Holmes et al., 2008). Emotion-related 
P1 effects, however, were not modified by trait anxiety. There are relatively few studies examining links between anxiety and ERP responses to expressive faces, but, of those conducted, effects of anxiety on early sensory components such as the $\mathrm{P} 1$ have been reported by some groups (e.g., Holmes et al., 2008; Li, Zinbarg, Boehm, \& Paller, 2008) but not others (e.g., Bar-Haim, Lamy, \& Glickman, 2005). Further work is needed to examine the influence of anxiety on posterior components triggered by emotional expressions.

The finding of an enhanced EPN to fearful and happy compared with neutral facial expressions is also consistent with previous findings in which the EPN was found to be greater in amplitude to threatening (e.g., Eimer et al., 2003; Sato et al., 2001; Schupp et al., 2004) or friendly (e.g., Marinkovic \& Halgren, 1998; Schacht \& Sommer, 2009), relative to neutral, faces. The emotion-linked EPN was observed to be less pronounced in high than in low trait anxious participants, which is also consistent with some previous results (Holmes et al., 2008). The reason for the attenuation of the EPN to emotional faces in anxious individuals (an effect that remained after controlling for depression) is unclear, but the dissociation of this pattern from typical anxiety-related effects on the P1 component (i.e., amplification or no effect) suggests that these components may not reflect the same underlying process, contrary to some proposals (see Eimer \& Holmes, 2007; Vuilleumier \& Pourtois, 2007).

Notably, our emotion-related P1 and EPN effects were not affected by task load. In other words, the P1 and EPN emotion effects were immune to interference from task demands, indicating that early perceptual stages of emotion processing may not be subject to these particular variations in task difficulty. By contrast, early sensory component effects elicited by emotional faces in previous ERP studies were found to be abolished by spatial attention filtering (e.g., Eimer et al., 2003; Holmes et al., 2003). The present results indicate that enhanced sensory signals for salient affective representations, possibly via amygdala feedback to sensory representation areas (e.g., Anderson \& Phelps, 2001; Vuilleumier, Richardson, Armony, Driver, \& Dolan, 2004), may be independent of the availability of information processing resources under circumstances in which the stimuli fall within focal (spatial) attention (see also Holmes, Kiss, \& Eimer, 2006).

For frontocentral components (early- and late-phase LPP) elicited during the low-load task, fearful faces triggered enhanced ERP effects relative to neutral faces, starting at about $180 \mathrm{msec}$ after stimulus onset and remaining present as an augmented LPP throughout the $700-\mathrm{msec}$ recording interval. These enhancements to fearful faces closely resemble findings from previous ERP studies (e.g., Ashley et al., 2004; Eimer \& Holmes, 2002; Williams, Palmer, Liddell, Song, \& Gordon, 2006). In contrast to the positive deflections at frontocentral locations elicited by fearful faces, happy emotional faces produced significant activation within the early phase $(180-400 \mathrm{msec})$ of the LPP, but not within the late phase LPP (400-700 msec) time window. These more transient frontocentral emotional expression effects for happy faces are consistent with findings from a number of recent electrophysiological observations (e.g., Ashley et al., 2004; Holmes et al., 2008; Williams et al., 2006). Furthermore, there were no significant differences in the magnitude of the emotional expression ERP positivities between low and high trait anxious groups. The absence of anxiety-related effects on frontocentral components under low task load conditions replicates findings from a previous study in which the same 1-back task was employed (Holmes et al., 2008). In fact, Holmes et al. (2008) found a trend toward reduced ERP differences between fearful and neutral faces in high trait anxious participants, similar to anxiety-mediated reductions in longer-latency components to threatening expressions shown in some previous studies (e.g., Felmingham, Bryant, \& Gordon, 2003; Rossignol, Philippot, Douilliez, Crommelinck, \& Campanella, 2005). ${ }^{3}$ Reduced ERP effects to negative faces have been suggested to index a rapid form of cognitive avoidance, following the initial vigilance that is reflected by enhanced $\mathrm{P} 1$ or EPN effects (Holmes et al., 2008).

Crucially, although ERPs to emotional faces were unaffected by trait anxiety in the low-load condition, frontocentral effects for fearful and happy faces were found to be modulated by trait anxiety level in the high-load task condition. Here, high trait anxious participants showed more pronounced LPP effects (early and late phase) in response to fearful and happy faces, compared with low trait anxious participants, whose emotion-specific ERP responses were all but eliminated. This finding suggests that in low trait anxious individuals, task difficulty or load can influence frontocentral components involved in the detection of new significant stimuli in working memory (early phase) and in the controlled storage or maintenance of the stimulus representations (late phase; see, e.g., Eimer \& Holmes, 2007; Schupp et al., 2006; Vuilleumier $\&$ Pourtois, 2007). However, in high trait anxious participants, processes related to the detection and maintenance of emotional stimuli in working memory are seemingly immune to these variations in task difficulty. It should be noted at this point that these effects were not specific to trait anxiety, because they were no longer evident when controlling for depression. This is perhaps not surprising in light of the high colinearity between anxiety and depression scores, and it reinforces our use of the term anxiety to distinguish nonspecific distress from "pure anxiety." The mechanisms that might underlie these interactions will now be considered.

One possible explanation for the elimination of frontocentral emotional expression effects in low trait anxious participants, compared with the retention of these effects in high trait anxious participants, under high-load conditions, is that low, relative to high, anxious individuals may have found the high-load task more difficult and therefore had fewer processing resources available for memory consolidation operations on emotional face content. Behavioral performance on the task, however, showed no evidence of poorer accuracy in low trait anxious participants. It therefore seems unlikely that differences arising in ability to perform the task would have been responsible for the differential ERP effects. A second possible expla- 
nation is that differences arose in the perceptual strategies that high and low trait anxious participants used for the 2-back task. For example, high trait anxious participants may have been focusing their attention more on the emotion-relevant features of the faces, whereas, in order to perform the task, low trait anxious participants possibly focused more on identity-relevant characteristics. By this account, we would also have to assume that high and low trait anxious group strategies would have been equivalent during the 1-back task, since emotional expression ERP effects here did not differ. It is not immediately apparent, however, why anxiety group strategies would be the same for the 1-back task but would differ for the 2-back task. A third, and possibly more convincing, account is that enhanced processing load (i.e., from the retention and comparison of multiple faces in precise temporal order in working memory) had a differential impact on the encoding of emotional expressions across high and low trait anxiety groups. No significant emotional expression effects were generated under conditions of high task load in low trait anxious participants, suggesting that frontocentral emotional expression responses, reflecting short-term memory consolidation and retention, may depend on the availability of cognitive resources in this group. By contrast, frontocentral emotional expression effects arose in individuals with high levels of trait anxiety, regardless of the availability of processing resources, suggesting that the processing of fearful and happy facial expressions proceeded unintentionally and effortlessly.

It is not entirely clear what mechanisms might be involved in the enhanced automaticity for the processing of emotional faces in high trait anxious participants. It has been suggested that anxious individuals possess hypersensitive automatic threat-evaluation mechanisms, mediated by the amygdala and related subcortical structures (see, e.g., Bar-Haim et al., 2007; Mathews \& Mackintosh, 1998; Mogg \& Bradley, 2004). We speculate that a propensity for this threat-evaluation system to "tag" potentially aversive stimuli with higher threat value in anxious individuals (see, e.g., Eimer \& Holmes, 2007; Taylor \& Fragopanagos, 2005) may increase the probability that current task processing will be interrupted, with a redirection of attentional resources toward the encoding of the threat stimulus. In other words, threatening information may exert a circuit-breaking action that disrupts attentional control and goal-directed activity (e.g., Taylor \& Fragopanagos, 2005; see also Corbetta, Patel, \& Shulman, 2008). However, it should be noted that the modulatory effects of anxiety were present not only for fearful faces, but also for happy faces. Therefore, an explanation in terms of a hypersensitive emotion-evaluation system may be more appropriate (see, e.g., Bradley et al., 1999; Garner et al., 2006). One problem with this general account is that a redirection of attention from one process (performing a 2-back task) to another (encoding and consolidating emotionally laden events in working memory) might also be expected to disrupt behavioral (i.e., accuracy) performance on the 2-back task, but there was no evidence of this. It is known, however, that high trait anxious partici- pants often employ strategies, such as enhanced mental effort and recruitment of additional processing resources, to compensate for disruptions to current task processing and to maintain performance effectiveness (see Eysenck, Derakshan, Santos, \& Calvo, 2007); it is possible that similar strategies were adopted here.

To conclude, the present study supports the idea that processes involved in the enhancement of emotional stimulus representations in sensory cortical areas arise regardless of the availability of cognitive resources, in contrast to their dependence on spatial attention resources (see Eimer \& Holmes, 2007). However, processes involved in the registration and storage of emotion-related information in working memory may rely to an extent on the availability of processing resources, but this is modified by anxiety level, with a stronger resistance to variations in resources in high than in low trait anxious individuals. In sum, we tentatively conclude that anxiety is associated with greater automaticity of processing of emotion-related information when cognitive resources are unavailable for the control of attention. Our results also support the idea that automaticity is not an all-ornone concept (Bargh, 1989) and that the inclusion of measures of anxiety is crucial to the development of our understanding of attention-emotion interactions (cf. Fox et al., 2005). In future ERP studies, it will be important to examine the impact of different forms of processing load - for example, how manipulations of either perceptual or cognitive load (see, e.g., Bishop, 2007; Lavie, 2005) affect emotional facial expression processing or the spatial filtering of emotional stimuli.

\section{AUTHOR NOTE}

The present research has been supported by an internal grant from Roehampton University. The authors thank Paul Bretherton for his technical assistance and three anonymous reviewers for their helpful comments on an earlier draft of the manuscript. Address correspondence to A. Holmes, School of Human and Life Sciences, Roehampton University, Whitelands College, Holybourne Avenue, London SW15 4JD, England (e-mail: a.Holmes@roehampton.ac.uk).

\section{REFERENCES}

Adolphs, R., Russell, J. A., \& Tranel, D. (1999). A role for the human amygdala in recognizing emotional arousal from unpleasant stimuli. Psychological Science, 10, 167-171.

Anderson, A. K., \& Phelps, E. A. (2001). Lesions of the human amygdala impair enhanced perception of emotionally salient events. $\mathrm{Na}$ ture, 411, 305-309.

Ashley, V., Vuilleumier, P., \& Swick, D. (2004). Time course and specificity of event-related potentials to emotional expressions. NeuroReport, 15, 211-216.

BARGH, J. A. (1989). Conditional automaticity: Varieties of automatic influence in social perception and cognition. In J. S. Uleman \& J. A. Bargh (Eds.), Unintended thought (pp. 3-51). London: Guilford.

BAR-HAim, Y., LAmy, D., \& Glickman, S. (2005). Attentional bias in anxiety: A behavioral and ERP study. Brain \& Cognition, 59, 11-22.

Bar-Haim, Y., Lamy, D., Pergamin, L., Bakermans-Kranenburg, M. J., \& VAN IJZENDOORN, M. H. (2007). Threat-related attentional bias in anxious and nonanxious individuals: A meta-analytic study. Psychological Bulletin, 133, 1-24.

Batty, M., \& TAylor, M. J. (2003). Early processing of the six basic facial emotional expressions. Cognitive Brain Research, 17, 613-620. 
Beck, A. T., Ward, C. H., Mendelson, M., Mock, J., \& Erbaugh, J. (1961). An inventory for measuring depression. Archives of General Psychiatry, 4, 561-571.

BisHop, S. J. (2007). Neurocognitive mechanisms of anxiety: An integrative account. Trends in Cognitive Sciences, 11, 307-316.

Bradley, B. P., Mogg, K., White, J., Groom, C., \& de Bono, J. (1999). Attentional bias for emotional faces in generalized anxiety disorder. British Journal of Clinical Psychology, 38, 267-278.

Byrne, A., \& EySENCK, M. W. (1995). Trait anxiety, anxious mood, and threat detection. Cognition \& Emotion, 9, 549-562.

Chen, E., Lewin, M. R., \& Craske, M. G. (1996). Effects of state anxiety on selective processing of threatening information. Cognition \& Emotion, 10, 225-240.

ClARK, L. A., \& WATSON, D. (1991). Tripartite model of anxiety and depression: Psychometric evidence and taxonomic implications. Journal of Abnormal Psychology, 100, 316-336.

Corbetta, M., Patel, G., \& Shulman, G. L. (2008). The reorienting system of the human brain: From environment to theory of mind. Neuron, 58, 306-324.

Dolan, R. J., \& Vuilleumier, P. (2003). Amygdala automaticity in emotional processing. In P. Shinnick-Gallagher, A. Pitkänen, A. Shekhar, \& L. Cahill (Eds.), The amygdala in brain function: Basic and clinical approaches (Annals of the New York Academy of Sciences, Vol. 985, pp. 348-355). New York: New York Academy of Sciences.

Eastwood, J. D., Smilek, D., \& Merikle, P. M. (2001). Differential attentional guidance by unattended faces expressing positive and negative emotion. Perception \& Psychophysics, 63, 1004-1013.

Eger, E., Jedynak, A., Iwaki, T., \& Skrandies, W. (2003). Rapid extraction of emotional expression: Evidence from evoked potential fields during brief presentation of face stimuli. Neuropsychologia, 41, 808-817.

EIMER, M., \& Holmes, A. (2002). An ERP study on the time course of emotional face processing. NeuroReport, 13, 427-431.

Eimer, M., \& Holmes, A. (2007). Event-related brain potential correlates of emotional face processing. Neuropsychologia, 45, 15-31.

Eimer, M., Holmes, A., \& McGlone, F. P. (2003). The role of spatial attention in the processing of facial expression: An ERP study of rapid brain responses to six basic emotions. Cognitive, Affective, \& Behavioral Neuroscience, 3, 97-110.

Ekman, P., \& Friesen, W. V. (1976). Pictures of facial affect. Palo Alto, CA: Consulting Psychologists Press.

Endler, N. S., Cox, B. J., PARKer, J. D. A., \& Bagby, R. M. (1992). Selfreports of depression and state-trait anxiety: Evidence for differential assessment. Journal of Personality \& Social Psychology, 63, 832-838.

Eysenck, M. W., Derakshan, N., Santos, R., \& Calvo, M. G. (2007). Anxiety and cognitive performance: The processing efficiency theory. Emotion, 7, 336-353.

Felmingham, K. L., Bryant, R. A., \& Gordon, E. (2003). Processing angry and neutral faces in post-traumatic stress disorder: An eventrelated potentials study. NeuroReport, 14, 777-780.

Fountoulakis, K. N., Bech, P., Panagiotidis, P., Siamouli, M., Kantartzis, S., Papadopoulou, A., ET AL. (2007). Comparison of depressive indices: Reliability, validity, relationship to anxiety and personality and the role of age and life events. Journal of Affective Disorders, 97, 187-195.

Fox, E. (2002). Processing emotional facial expressions: The role of anxiety and awareness. Cognitive, Affective, \& Behavioral Neuroscience, 2, 52-63.

Fox, E. (2004). Maintenance or capture of attention in anxiety-related biases? In J. Yiend (Ed.), Cognition, emotion and psychopathology: Theoretical, empirical and clinical directions (pp. 86-105). Cambridge: Cambridge University Press.

Fox, E., Derakshan, N., \& Shoker, L. (2008). Trait anxiety modulates the electrophysiological indices of rapid spatial orienting towards angry faces. NeuroReport, 19, 259-263.

Fox, E., Russo, R., Bowles, R. J., \& Dutton, K. (2001). Do threatening stimuli draw or hold visual attention in subclinical anxiety? Journal of Experimental Psychology: General, 130, 681-700.

Fox, E., Russo, R., \& Georgiou, G. A. (2005). Anxiety modulates the degree of attentive resources required to process emotional faces. Cognitive, Affective, \& Behavioral Neuroscience, 5, 396-404.

Garner, M., Mogg, K., \& Bradley, B. P. (2006). Orienting and main- tenance of gaze to facial expressions in social anxiety. Journal of Abnormal Psychology, 115, 760-770.

Halgren, E., RaiJ, T., Marinkovic, K., Jousmaki, V., \& Hari, R. (2000). Cognitive response profile of the human fusiform face area as determined by MEG. Cerebral Cortex, 10, 69-81.

Holmes, A., Bradley, B. P., Kragh Nielsen, M., \& Mogg, K. (2009). Attentional selectivity for emotional faces: Evidence from human electrophysiology. Psychophysiology, 46, 62-68.

Holmes, A., Green, S., \& Vuilleumier, P. (2005). The involvement of distinct visual channels in rapid attention towards fearful facial expressions. Cognition \& Emotion, 19, 899-922.

Holmes, A., Kiss, M., \& Eimer, M. (2006). Attention modulates the processing of emotional expression triggered by foveal faces. Neuroscience Letters, 394, 48-52.

Holmes, A., Kragh Nielsen, M., \& Green, S. (2008). Effects of anxiety on the processing of fearful and happy faces: An event-related potential study. Biological Psychology, 77, 159-173.

Holmes, A., Richards, A., \& Green, S. (2006). Anxiety and sensitivity to eye gaze in emotional faces. Brain \& Cognition, 60, 282-294.

Holmes, A., Vuilleumier, P., \& Eimer, M. (2003). The processing of emotional facial expression is gated by spatial attention: Evidence from event-related brain potentials. Cognitive Brain Research, 16, 174-184.

Holmes, A., Winston, J. S., \& Eimer, M. (2005). The role of spatial frequency information for ERP components sensitive to faces and emotional facial expression. Cognitive Brain Research, 25, 508-520.

Krolak-Salmon, P., Fischer, C., Vighetto, A., \& Mauguière, F. (2001). Processing of facial emotional expression: Spatio-temporal data as assessed by scalp event-related potentials. European Journal of Neuroscience, 13, 987-994.

Lavie, N. (2005). Distracted and confused?: Selective attention under load. Trends in Cognitive Sciences, 9, 75-82.

Li, W., Zinbarg, R. E., Boehm, S. G., \& Paller, K. A. (2008). Neural and behavioral evidence for affective priming from unconsciously perceived emotional facial expressions and the influence of trait anxiety. Journal of Cognitive Neuroscience, 20, 95-107.

Marinkovic, K., \& Halgren, E. (1998). Human brain potentials related to the emotional expression, repetition, and gender of faces. Psychobiology, 26, 348-356.

Mathews, A., \& Mackintosh, B. (1998). A cognitive model of selective processing in anxiety. Cognitive Therapy \& Research, 22, 539-560.

Miltner, W. H. R., Trippe, R. H., Krieschel, S., Gutberlet, I., Hecht, H., \& Weiss, T. (2005). Event-related brain potentials and affective responses to threat in spider/snake-phobic and non-phobic subjects. International Journal of Psychophysiology, 57, 43-52.

MogG, K., \& Bradley, B. P. (1999). Orienting of attention to threatening facial expressions presented under conditions of restricted awareness. Cognition \& Emotion, 13, 713-740.

MogG, K., \& Bradley, B. P. (2004). A cognitive-motivational perspective on the processing of threat information and anxiety. In J. Yiend (Ed.), Cognition, emotion and psychopathology: Theoretical, empirical and clinical directions (pp. 68-85). Cambridge: Cambridge University Press.

Mogg, K., \& Marden, B. (1990). Processing of emotional information in anxious subjects. British Journal of Clinical Psychology, 29, 227-229.

Münte, T. F., Brack, M., Grootheer, O., Wieringa, B. M., Matzke, M., \& Johannes, S. (1998). Brain potentials reveal the timing of face identity and expression judgments. Neuroscience Research, 30, 25-34.

Olofsson, J. K., Nordin, S., Sequeira, H., \& Polich, J. (2008). Affective picture processing: An integrative review of ERP findings. Biological Psychology, 77, 247-265.

Palermo, R., \& Rhodes, G. (2007). Are you always on my mind? A review of how face perception and attention interact. Neuropsychologia, 45, 75-92.

PessoA, L. (2005). To what extent are emotional visual stimuli processed without attention and awareness? Current Opinion in Neurobiology, 15, 188-196.

Pessoa, L., McKenna, M., Gutierrez, E., \& Ungerleider, L. G. (2002). Neural processing of emotional faces requires attention. Proceedings of the National Academy of Sciences, 99, 11458-11463. 
Pessoa, L., Padmala, S., \& Morland, T. (2005). Fate of unattended fearful faces in the amygdala is determined by both attentional resources and cognitive modulation. NeuroImage, 28, 249-255.

Pizzagalli, D., Regard, M., \& Lehmann, D. (1999). Rapid emotional face processing in the human right and left brain hemispheres: An ERP study. NeuroReport, 10, 2691-2698.

Polich, J. (2007). Updating P300: An integrative theory of P3a and P3b. Clinical Neurophysiology, 118, 2128-2148.

Pourtois, G., Dan, E. S., Grandjean, D., Sander, D., \& VuilleuMIER, P. (2005). Enhanced extrastriate visual response to bandpass spatial frequency filtered fearful faces: Time course and topographic evoked-potentials mapping. Human Brain Mapping, 26, 65-79.

Pourtois, G., Grandjean, D., Sander, D., \& Vuilleumier, P. (2004) Electrophysiological correlates of rapid spatial orienting towards fearful faces. Cerebral Cortex, 14, 619-633.

Rossignol, M., Philippot, P., Douilliez, C., Crommelinck, M., \& Campanella, S. (2005). The perception of fearful and happy facial expression is modulated by anxiety: An event-related potential study. Neuroscience Letters, 377, 115-120.

Santesso, D. L., Meuret, A. E., Hofmann, S. G., Mueller, E. M., Ratner, K. G., Roesch, E. B., \& Pizzagalli, D. A. (2008). Electrophysiological correlates of spatial orienting towards angry faces: A source localization study. Neuropsychologia, 46, 1338-1348.

Sato, W., Kochiyama, T., YoshiKawa, S., \& Matsumura, M. (2001). Emotional expression boosts early visual processing of the face: ERP recording and its decomposition by independent component analysis. NeuroReport, 26, 709-714.

SCHAcht, A., \& Sommer, W. (2009). Emotions in word and face processing: Early and late cortical responses. Brain \& Cognition, 69, 538-550.

Schneider, W., Eschman, A., \& Zuccolotto, A. (2002). E-Prime reference guide. Pittsburgh, PA: Psychology Software Tools.

Schupp, H. T., Flaisch, T., Stockburger, J., \& JunghöFer, M. (2006). Emotion and attention: Event-related potential studies. Progress in Brain Research, 156, 31-51.

Schupp, H. T., Öhman, A., Junghöfer, M., Weike, A. I., StockBURger, J., \& HAMm, A. O. (2004). The facilitated processing of threatening faces: An ERP analysis. Emotion, 42, 189-200.

Spielberger, C. D., Gorsuch, R. L., Lushene, R., VAGG, P. R., \& JACoBs, G. A. (1983). Manual for the State-Trait Anxiety Inventory. Palo Alto, CA: Consulting Psychologists Press.

Streit, M., Ioannides, A. A., Liu, L., Wölwer, W., Dammers, J., Gross, J., ET AL. (1999). Neurophysiological correlates of the recognition of facial expressions of emotion as revealed by magnetoencephalography. Cognitive Brain Research, 7, 481-491.
TaYlor, J. G., \& Fragopanagos, N. F. (2005). The interaction of attention and emotion. Neural Networks, 18, 353-369.

Tsuchiya, N., \& Adolphs, R. (2007). Emotion and consciousness. Trends in Cognitive Sciences, 11, 158-167.

Vuilleumier, P., \& Pourtois, G. (2007). Distributed and interactive brain mechanisms during emotion face perception: Evidence from functional neuroimaging. Neuropsychologia, 45, 174-194.

Vuilleumier, P., Richardson, M. P., Armony, J. L., Driver, J., \& Dolan, R. J. (2004). Distant influences of amygdala lesion on visual cortical activation during emotional face processing. Nature Neuroscience, 7, 1271-1280.

Vuilleumier, P., \& Schwartz, S. (2001). Beware and be aware: Capture of spatial attention by fear-related stimuli in neglect. NeuroReport, 12, 1119-1122.

Williams, L. M., Palmer, D., Liddell, B. J., Song, L., \& Gordon, E. (2006). The "when" and "where" of perceiving signals of threat versus non-threat. NeuroImage, 31, 458-467.

Wright, C. I., Martis, B., McMullin, K., Shin, L. M., \& Rauch, S. L. (2003). Amygdala and insular responses to emotionally valenced human faces in small animal specific phobia. Biological Psychiatry, 54, 1067-1076.

\section{NOTES}

1. Although a number of previous studies have found equivalent arousal ratings for fearful and happy facial expressions from the Ekman and Friesen (1976) series (e.g., Adolphs, Russell, \& Tranel, 1999; Wright, Martis, McMullin, Shin, \& Rauch, 2003), participants were not asked to rate the faces for arousal in this study, and so we cannot completely rule out the possibility that any dissociable effects of happy relative to fearful faces could be explicable in terms of arousal rather than valence differences.

2. A comparison of ERPs elicited on 1- and 2-back target trials would have served as a further check that participants were attending to stimuli in both task conditions. Unfortunately, we were unable to carry out this analysis because of the low numbers of accepted trials following artifact rejection.

3. Note, however, that enhanced LPPs tend to be observed in anxious participants in studies employing more intense nonface threat images (e.g., Miltner et al., 2005; Schupp et al., 2006).

(Manuscript received November 8, 2008; revision accepted for publication June 29, 2009.) 